\title{
O desenvolvimento sustentável nas imagens do Repórter Eco: o projeto Baru como modelo
}

\author{
Lucia de Fátima Estevinho Guido ${ }^{1}$ \\ Universidade Federal de Uberlândia \\ Cristina Bruzzo ${ }^{2}$ \\ Universidade Estadual de Campinas
}

resumo: Este trabalho discute a idéia de desenvolvimento sustentável veiculada em um programa de televisão, o Repórter Eco - TV Cultura. Tendo em vista a importância de observar o modo como informações ecológicas são apresentadas na mídia, selecionamos sete edições do referido programa para analisar em profundidade algumas de suas reportagens. Neste texto, apresentaremos a análise de uma reportagem que trata do manejo sustentável do baru, uma árvore típica do Cerrado e que serviu de inspiração para o nome de um projeto de manejo sustentável da região do entorno do município de Goiânia, GO. Verificamos que a reportagem sobre o Projeto Baru não ressalta as contradições existentes entre as diferentes posições relativas à conservação dos recursos naturais, nem polemiza o desenvolvimento sustentável em face da atividade coletora.

palavras-chave: Desenvolvimento sustentável, Televisão, População tradicional.

abstract: This work reflects on the idea of sustainable development as it is transmitted in the TV series Repórter Eco - TV Cultura Network. Considering the importance of paying attention to how ecological news is presented by the media, we have selected seven editions of the series in order to analyze some of their reportings in depth. In this text, we will show an analysis of a reporting that deals with sustainable manipulation of baru, a typical tree of Cerrado which inspired the name of a sustainable manipulation project in the region around the city of Goiânia, GO. We have verified that the news article about Baru Project does not emphasize

\footnotetext{
1 e-mail: lucia@umuarama.ufu.br

2 e-mail: bruzzo@unicamp.br
} 
the existing contradictions among differing positions related to the natural resources preservation, neither creates any controversy about sustainable development in relation to collecting (goods, materials) from nature.

keywords: Sustainable development, Television, Traditional population.

\section{Introdução}

No mesmo ano em que ocorreu a Rio-92, estreou na TV Cultura o programa Repórter Eco, que, durante estes 15 anos, tem-se dedicado aos temas ambientais e ecológicos. Este texto discute a idéia de desenvolvimento sustentável veiculada em uma edição desse programa, buscando examinar como a televisão trata as questões ambientais. A televisão foi apontada em várias pesquisas, realizadas em diferentes locais, como o meio principal de divulgação de informações ambientais para alunos e professores (CARVALHO, 1986; BORTOLOZZI, 1997; GUIDO, 2000; MÁXIMO-ESTEVES, 1998; OSTMAN; PARKER, 1986).

Entre os veículos de comunicação de massa $^{3}$, a televisão é objeto de muitos estudos que abordam sua estrutura tecnológica e finalidade mercadológica, entre outras análises. Entretanto, são poucos os trabalhos que analisam a televisão dirigindo um olhar mais atento para os produtos que ela efetivamente produz, como, por exemplo, os programas (MACHADO, 2001).

Tendo como foco os programas de televisão que veiculam informações ecológicas, voltamos nossa atenção inicialmente para

\footnotetext{
3 A televisão é sem dúvida o veículo da cultura de massa com maior penetração na sociedade, por isso ela é objeto de crítica dos adeptos das teses da Escola de Frankfurt. Esse movimento filosófico da primeira metade do século passado reuniu um conjunto de pensadores em torno do Instituto de Pesquisa Social da Universidade de Frankfurt, partilhando temas comuns de análise, tais como a alienação do indivíduo nas modernas sociedades industriais e o papel dos meios de comunicação de massa na produção dessa alienação.
} 
algumas edições do programa Repórter Eco, que foram captadas e gravadas na cidade de Uberlândia, MG.

$\mathrm{Na}$ análise das imagens, procuramos observar: sua origem, se captadas no local da reportagem ou oriundas de um banco de arquivos; a presença de legendas indicando as suas fontes; a sua edição. Os enquadramentos - o uso de recursos como close e superclose — foram analisados para buscar o endereçamento pretendido pela equipe de reportagem. A edição foi examinada atentando-se para a seqüência das cenas e para os elementos que estabeleciam ligação entre as seqüências.

Em relação à banda sonora, observamos: o uso de música; do som ambiente; a locução e seus encadeamentos; os depoimentos e as falas. A edição da fala foi importante para percebermos os cortes, as pessoas selecionadas, o tempo dedicado a cada depoimento, a quem é dada a fala conclusiva.

A análise do conjunto desses elementos da construção de significação na televisão teve o objetivo de examinar o tratamento dado pelo programa a respeito de uma questão polêmica: as ambigüidades entre preservação e exploração econômica no desenvolvimento sustentável.

\section{O Projeto Baru como modelo de desenvolvimento sustentável}

A reportagem selecionada para análise foi exibida no dia 26/05/2002 e trata do manejo sustentável do baru, uma árvore típica do Cerrado e que serviu de inspiração para o nome de um projeto de manejo sustentável da região do entorno do município de Goiânia, sob responsabilidade do Centro de Desenvolvimento Agroecológico do Cerrado (CEDAC).

Faremos as descrições das cenas que compõem essa reportagem intercalando-as com nossas análises. As imagens assim fragmentadas ficam separadas do seu conjunto e produzem um outro significado que muitas vezes não fica evidente à primeira vista.

Flávia Lippi, apresentadora do Repórter Eco, anuncia a reportagem com as seguintes palavras: "A rica biodiversidade brasileira. $\mathrm{O}$ quadro sobre biodiversidade, resultado da parceria entre a TV 
Cultura e a Natura, apresenta a quarta reportagem da série sobre o Balanço da Rio-92. Você vai conhecer o Projeto Baru, exemplo de desenvolvimento econômico aliado à preservação do Cerrado".

Logo no início da reportagem, aparecem pessoas andando na praça de uma pequena cidade; acompanha essa primeira seqüência a legenda com o nome e a localização do lugar: Caldą̧inha/GO. A seguir, uma série de imagens ocupa a tela: pessoas andando a cavalo, uma casa rodeada por árvores, cercas, porteira, vacas pastando. O trecho inicial é encerrado com a exibição de árvores de pequeno porte espaçadas umas das outras, entremeadas de capim. São focalizados também lugares com vegetação exuberante, ângulo fechado na copa das árvores. Esta última seqüência de imagens parece querer mostrar a vegetação típica do Cerrado e a existência de uma mata. Tal idéia fica evidente na locução em off ${ }^{4}$ que acompanha as imagens:

A pequena Caldazinha fica a 35 quilômetros de Goiânia. A paisagem mais comum é o Cerrado devastado pelo cultivo da soja e pela agropecuária. Cenário semelhante em pelo menos $80 \%$ do Cerrado brasileiro. Pequenas áreas ainda conservam uma riqueza que faz do Cerrado um dos hot spots do planeta: regiões mais ricas em biodiversidade e também as mais ameaçadas. A comunidade Boa Esperança vive na fronteira entre a conservação e a devastação deste bioma.

Essa locução inicial, além de situar geograficamente o projeto, antecipa o problema que a reportagem irá abordar: a devastação do Cerrado, com sugestões de manejo sustentável para a região de Goiânia, que poderá ajudar na conservação desse bioma. Aborda-se, assim, a situação específica da pequena Caldazinha para inseri-la no âmbito regional: o Cerrado, relatando-se a extensão da sua devastação. As imagens que acompanham essa locução mostram primeiramente uma cidade pequena, pacata, as pessoas na praça, para depois focar as

\footnotetext{
4 A expressão "locução em off' é usada tanto no Brasil como na França para as situações em que a fonte emissora da voz não aparece no momento em que a ouvimos.
} 
pessoas no campo, o gado, finalizando com uma mata sem a presença humana. Esta última seqüência pretende ilustrar o que a locução diz sobre o bioma Cerrado: um dos hot spots do planeta.

O termo hot spots diz respeito a regiões ameaçadas de extinção que possuem grande diversidade de espécies e que, portanto, devem ser preservadas. Os critérios para a definição desse termo são de ordem quase estritamente biológica, não se levando em conta a importância da presença humana nessas regiões (DIEGUES; ARRUDA, 2001).

Outro termo que chama a atenção pelo sentido figurado a ele atribuído pela locução é o de fronteira. A locução situa a comunidade Boa Esperança na fronteira entre a conservação e a devastação, salientando que nem tudo está perdido. A palavra fronteira estabelece o limite vislumbrado na reportagem e revela a idéia segundo a qual o que deve ser protegido tem a sua delimitação, uma vez que existe a fronteira entre o que é preservado e o que é degradado, dando uma idéia antiga de conservação. A posição expressa na edição do texto e visualizada nas imagens não atenta para as inovações introduzidas pela biologia da conservação, que atualmente propõe não a idéia de fronteira, mas a de corredor ecológico, pois a conservação da natureza depende da interligação das áreas protegidas, o que contribui para uma maior variabilidade genética entre as espécies, atenuando a perda de biodiversidade, decorrente da exploração econômica da natureza. A esse respeito, é relevante o seguinte raciocínio:

Veja-se, por exemplo, a teoria dos refúgios, que serviu de base, nas décadas de 1970 e 1980, para o estabelecimento de parques nacionais na Amazônia, verdadeiras ilhas de conservação, e que depois passaram ao desuso. Hoje fala-se em "corredor ecológico" como forma de resolver a insularização das unidades de conservação, apesar de ser uma estratégia não devidamente avaliada pela sociedade brasileira, nem na sua complexidade ecológica nem na social e política (DIEGUES; ARRUDA, 2001, p.34).

$\mathrm{Na}$ reportagem dedicada ao Projeto Baru, o termo fronteira enfatiza a delimitação de espaços para a conservação, uma definição de limite que está defasada quando abordamos os estudos mais recentes 
sobre conservação. No entanto, o programa não polemiza, não discute e, portanto, não apresenta visões diferentes daquela de fronteira. As imagens que acompanham essa locução mostram um local com vegetação rasteira (gramínea) com gado, tendo ao fundo uma casa, uma porteira e uma cerca. O movimento da câmera — um travelling ${ }^{5}$ — dá a sensação de que passamos pela porteira em meio à cerca que delimita o espaço do gado. Mostrar a passagem pela cerca no momento em que a palavra fronteira está sendo falada na locução reforça a idéia de limite, de separação entre um domínio e outro.

Após a locução inicial, conforme a descrição acima, a reportagem apresenta os depoimentos de dois moradores locais, filmados em primeiro plano ${ }^{6}$, tendo ao fundo uma casa simples, de cor amarela, rodeada por plantas e chão de terra batida: "Nós somos todos pequenos proprietários. E a gente não queria, não quer ir para a cidade" (Terezinha Rodrigues Campos, Presidente da Associação Boa Esperança). "O agricultor tem dificuldades, ele não tem como investir em soja e em outras produções maiores, então a gente hoje está investindo aqui para melhorar a qualidade do meio ambiente, trabalhando com coisas do Cerrado" (Jesus Lopes da Silva, Rede de Comercialização).

A reportagem prossegue e apresenta o Centro de Desenvolvimento Agroecológico do Cerrado (CEDAC). As imagens mostram uma casa com árvores ao redor, uma placa na frente da casa é focalizada rapidamente: "CEDAC - Centro de Desenvolvimento Agroecológico do Cerrado / Unidade de Beneficiamento de Produtos Agroecológicos do Cerrado / PROGRAMA / Rede de Comercialização Solidária de Agricultores Familiares e Extrativistas do Cerrado". A seguinte locução em off acompanha a imagem da placa: "O projeto para o manejo sustentável do baru é uma das formas de manter o homem no campo. Criado em 2000, o projeto é uma parceria das

\footnotetext{
5 Travellings: deslocamentos de câmera, por qualquer meio, para aproximar, afastar ou acompanhar um objeto. (ALMEIDA, 1994, p. 38).

${ }^{6}$ Primeiro Plano: A figura humana é enquadrada de meio busto para cima.

7 Em todas as transcrições, foram feitas pequenas alterações para adequação ao registro escrito.
} 
comunidades dos agricultores do CEDAC, Centro de Desenvolvimento Agropecuário do Cerrado”.

Essa locução, inserida logo após os depoimentos dos moradores locais, reforça a idéia de que essas pessoas podem continuar vivendo no campo. A Presidente da Associação Boa Esperança, Terezinha Rodrigues Campos, fala que não quer ir para a cidade e a locução em off diz que o projeto é uma das formas de manter o homem no campo. Mesmo que a moradora não diga que é o projeto que pode mantê-los no campo, o encadeamento que a locução realiza após essa fala conduz a tal entendimento. A parceria entre os agricultores também é evidenciada, mas não fica claro se o projeto surgiu entre eles ou se foi discutido em conjunto com o CEDAC, ou ainda se este último resgatou uma prática extrativista da região e a repassou para os moradores.

Um outro aspecto que chama a atenção nesse trecho da reportagem é que a locução em off entra em contradição com os dizeres da placa, pois há um uso impróprio dos conceitos agroecológico (placa) e agropecuário (locução em off) ${ }^{8}$, que são antagônicos. Nesse caso, como a imagem da placa é rápida, ela não permite a sua leitura, assim o telespectador pode não perceber a distorção dos conceitos. Mas, então, qual seria a função de mostrar a placa se não é possível realizar a leitura sem a gravação prévia da reportagem? No andamento da matéria, a equipe de reportagem utiliza esse tipo de recurso para dar existência ao CEDAC, para mostrar que a equipe esteve lá, pois mostrar o local faz parte do processo significante dos programas telejornalísticos? Contudo, a menção visual à placa não condiz com a linha editorial que orientou a edição da matéria: o agroecológico da placa tem pouca

\footnotetext{
${ }^{8} \mathrm{Na}$ edição do dia 04/07/2004, a reportagem foi reapresentada e essa locução foi modificada, reparando o erro conceitual apresentado. A palavra agropecuário foi substituída pela palavra agroecológico, o que mostra que alguém se preocupou em fazer essas correções e não outras.

${ }^{9}$ Machado (2001, p. 105) comenta que, ao longo de sua história, os telejornais foram construindo uma estrutura em que os depoimentos de sujeitos implicados na notícia fazem parte da reportagem, o que trouxe a necessidade de as câmeras estarem "no local e no tempo dos acontecimentos, não apenas para autorizá-la [a reportagem] como fonte confiável, mas principalmente porque essa é a condição sine qua non do seu processo significante".
} 
visibilidade, ao passo que o agropecuário, de conotação econômica, fica registrado nitidamente na locução em off.

O depoimento que vem logo em seguida traz esta característica dos programas informativos: mostrar o local do fato jornalístico e o depoimento das pessoas envolvidas com a matéria. A coordenadora técnica do CEDAC é filmada na frente da casa em que, na cena anterior, a placa foi rapidamente mostrada. A coordenadora diz: "Surgiu a necessidade de fazer um trabalho que pudesse melhorar a renda familiar, e uma proposta que surgiu foi o aproveitamento do baru. Foi a planta escolhida em função da facilidade de armazenamento, de beneficiamento, apesar de não ser conhecido nem pesquisado" (Alessandra Carla da Silva, Coordenadora Técnica do CEDAC).

Essa fala destaca as características do manejo sustentável, que objetiva a melhoria da renda familiar, o uso de técnicas simples e de impacto limitado sobre o meio ambiente.

As imagens que acompanham a locução em off e a fala da coordenadora do CEDAC mostram a coleta do baru por pessoas com vestimentas simples que, enfileiradas, entram em uma mata. Uma pessoa é destacada na cena, sendo possível notar que se trata da moradora Terezinha Rodrigues Campos (Presidente da Associação Boa Esperança). No interior da mata, as pessoas coletam o baru, colocandoo em sacos; a câmera focaliza os frutos no chão, uma mão coletando e os sacos em que o baru é acondicionado. Na continuação da cena, as pessoas, novamente enfileiradas, saem da mata com o saco parcialmente cheio nas costas; ouve-se ao fundo o som das pessoas cantando.

As cenas dessa coleta estão organizadas dentro de uma cronologia (pessoas aparecem entrando na mata, coletando os frutos no seu interior e depois saindo), o que oferece ao telespectador a sensação de que ele as acompanha no processo. Mas o que as imagens mostram para proporcionar a idéia de que o projeto é sobre manejo sustentável? Entrar e sair enfileirados da mata significa uma certa organização, visando uma proteção dessa mata, pois todos pisam no mesmo lugar. Cantar uma canção ao realizar o trabalho traz a idéia de que essa prática é antiga e conhecida por todos os envolvidos na coleta. 
Mas tais características são vagas e podem não se mostrar claras para o telespectador durante a apresentação do programa. É, portanto, a locução em off, seguida da fala da coordenadora do CEDAC, que dá a idéia de manejo sustentável ali praticado. Diz a locução: "O baru ainda é abundante na vegetação remanescente do Cerrado. É coletado em áreas dos próprios agricultores, ou de terceiros, seguindo os princípios da sustentabilidade". A fala da coordenadora técnica do CEDAC complementa:

A coleta do baru de forma é adequada, deixando partes dos frutos no pé para que a fauna silvestre possa se alimentar. E os agricultores extrativistas não colocariam mais fogo no Cerrado por causa do prejuízo ambiental que isso ocasiona. E não se teria mais o trabalho infantil, que é uma das condições, uma das premissas, porque em algumas regiões o trabalho infantil faz parte do extrativismo predatório.

A fala da coordenadora não elucida as imagens, tampouco tem relação com o que é mostrado na cena da coleta do baru, mas explica os princípios da sustentabilidade enunciados pela locução em off anterior à fala da coordenadora ${ }^{10}$.

Além da coleta do baru, o programa mostra cenas do seu beneficiamento e uma vOz em off acompanha as imagens que tentam mostrar tal processo, dizendo: "A unidade de processamento foi construída na comunidade de Boa Esperança". Na seqüência, o depoimento de uma moradora local explica como foi construída a unidade de processamento, destacando que a obra foi coletiva: "Desde

10 Essa dificuldade apresentada pelo Repórter Eco em discutir a idéia de desenvolvimento sustentável, como no trecho acima descrito, em que apenas os princípios da sustentabilidade são apresentados, é analisada por Bourdieu (1997, p. 19) como uma dificuldade do próprio meio televisivo, que, ao sofrer uma limitação de tempo, impõe limites ao discurso, reduz o que é apresentado, há uma espécie de censura exercida não só aos convidados como também aos jornalistas. Esse autor afirma que essa censura conduz a uma perda de autonomia relacionada "ao fato de que o assunto é imposto, de que as condições de comunicação são impostas, a limitação do tempo impõe ao discurso restrições tais que é pouco provável que alguma coisa possa ser dita”. 
o alicerce da indústria, a gente juntou pedra, entrou no mato para juntar pedra. Primeiro, foi um caminhão para juntar as pedras, depois não deu [sic] as pedras. As mulheres daqui, eu também junto, teve [sic] que ajudar, tudo, as indústrias, as mulheres que ajudaram também, com a ajuda dos homens também, (...) parceria". Entra pergunta em off da repórter: "Tá, aí foi difícil?""11 Resposta da moradora: "Foi, foi muito difícil, cansativo, a gente tinha que levantar cedinho, comia comida fria lá no mato, mas a gente sabia que ia ter melhora, né?” (Alessandra Miguel Rodrigues/ 19 anos). No retorno da locução em off, é oferecida a informação complementar:

A renda das famílias que trabalham na unidade de processamento aumentou, em média, de 300 para 600 reais por mês. O baru colhido nas outras seis comunidades é processado aqui. $\mathrm{O}$ equipamento ainda é rústico. Nestas imagens, elas simulam o processo de produção da farinha de baru, que começou a ser usada na merenda escolar da região noroeste de Goiânia, uma das mais carentes do município.

No trecho transcrito acima, aparece novamente o encadeamento das falas: locução em off, moradora e locução em off. Esta última complementa o que foi dito pela moradora Alessandra no final de sua fala, quando respondia à pergunta da repórter: “Tá, e aí foi difícil?”, ao que ela responde: "Foi, foi muito difícil, cansativo, [...], mas a gente sabia que ia ter melhora, né?". Logo em seguida, temos a locução em off, que diz: "A renda das famílias que trabalham na unidade de processamento aumentou em média [...]". Além de complementar a fala da moradora, a última locução destaca que o projeto melhorou a renda familiar, reforçando a idéia de que vale a pena permanecer morando no campo.

11 Percebemos nesse trecho uma busca em acelerar a reposta da moradora pela jornalista, que impõe um ritmo à entrevista, destacando o objetivo da jornalista com relação à fala da moradora. Mais uma vez, trazemos um comentário de Bourdieu (1997): muitas vezes inconscientemente, o apresentador impõe um ritmo à entrevista, cortando ou apressando a fala do entrevistado, conduzindo para um entendimento predeterminado. 
No momento em que a reportagem exibe o processamento do baru, a repórter que, na edição da matéria, é a responsável pela locução em off, diz: "Nestas imagens, elas simulam o processo de produção da farinha de baru". Ao proferir tais palavras, a repórter deixa transparecer que todas as outras imagens não são simulações, porque, se assim fosse, ela teria dito. Essa fala pretende aumentar a credibilidade das imagens anteriores, que reforçam o realismo do projeto. Dessa forma, a fala é usada para produzir e ampliar os significados das imagens.

Por outro lado, a simulação pode também levar o telespectador a duvidar de outras situações apresentadas, pois não é comum em programas desse tipo dizer que determinadas imagens são simulações. Porém, nesse caso, ao dizer que as imagens são uma simulação da produção de farinha do baru, a fala quer explicar algo que no momento das filmagens só podia ser simulado. Em cenas anteriores, nas quais aparecem algumas pessoas da comunidade Boa Esperança coletando o baru, temos também uma simulação, pois as suas atitudes, embora pareçam naturais, remetem a uma encenação, uma simulação dos trabalhos que são correntemente desenvolvidos pelos participantes do projeto: podemos ver, nessa encenação uma preocupação das pessoas em veicular uma conduta de respeito com o meio ambiente em atitudes que são restritas ao mundo privado. São situações utilizadas pelo meio televisivo, que servem para caracterizar o lugar, o projeto que está sendo realizado.

Outros produtos vendidos pela Rede de Comercialização Solidária são mostrados pela repórter da TV Cultura, que aparece no local da reportagem (legenda identifica Comunidade Boa Esperança $\mathrm{GO}$ ): uma sala de paredes brancas, com vários pacotes espalhados em cima de uma mesa. A câmera focaliza a etiqueta de um dos pacotes. Aparece a logomarca: "Empório do Cerrado". Maria Zulmira diz:

O Projeto Baru é o pontapé inicial de uma iniciativa inédita no Cerrado brasileiro, que é a criação de uma rede de comercialização solidária. Ela já reúne 330 famílias de agricultores extrativistas e familiares de 11 municípios do Estado de Goiás. Para dar identidade à rede, foi criada a marca Empório do Cerrado, que tem como símbolo uma espécie nativa, o Paepalanthus. A 
farinha do baru é o primeiro produto da rede de comercialização solidária. Outros derivados de espécies nativas vão seguir o mesmo caminho.

Maria Zulmira afirma que o projeto de manejo do baru é realizado por agricultores familiares e extrativistas que conseguem comercializar os seus produtos - tanto aqueles extraídos do baru quanto os demais - graças à rede solidária de comercialização. Essa informação valoriza o extrativismo sustentável, diferenciando-o do extrativismo predatório, diferenciação que já foi destacada na fala da coordenadora técnica do CEDAC, que, ao explicar o Projeto Baru, comentou sobre alguns cuidados que as comunidades estão tomando no desenvolvimento desse projeto, como a ausência de trabalho infantil e manejo adequado do solo, premissas do extrativismo sustentável, que o diferenciam do extrativismo predatório, em que tais práticas são usuais.

É importante lembrar que muitas relações comerciais nas regiões interioranas ainda são dominadas pelo sistema de aviamento, que se caracteriza pelo adiantamento ao pequeno produtor, nesse caso, o coletor que se encarrega de entregar aquilo que extrai da floresta a troco de produtos manufaturados de primeira necessidade. Essa relação comercial entre o patrão e o coletor teve sua origem no extrativismo do século XIX e início do século XX, com o ciclo da borracha estabelecido na Amazônia Central (PINTON; AUBERTIN, 2000).

A reportagem sobre o Projeto Baru valoriza as práticas comerciais introduzidas pela Rede de Comercialização Solidária, o que situa esse projeto naquilo que se convencionou chamar de manejo sustentável, que se utiliza de uma planta típica do Cerrado; conseqüentemente, o Projeto Baru serve de modelo para outras experiências. Daí as características que evidenciam o manejo sustentável serem valorizadas, como podemos observar nos depoimentos que fecham a reportagem, apresentados a seguir:

Sozinho a gente é fraco, mas quando a gente agrupa em um grupo maior a gente tem fortaleza para trabalhar junto. Quando a gente cria uma rede igual a gente criou essa rede de comercialização solidária, ela envolve um número maior de agricultores e facilita mais na produtividade. E também um 
aproveitamento maior [...] das coisas do Cerrado, né? (Jesus Lopes da Silva, Rede de comercialização).

Eu vou tá garantindo o meu futuro daqui para frente. (Alessandra Miguel Rodrigues, moradora local).

Mostrar a importância da conservação da biodiversidade e do valor disso. E do conhecimento das populações tradicionais do uso e do aproveitamento de forma sustentada. Eu acho que isso é reaplicável em qualquer bioma, em qualquer lugar do Brasil (Alessandra Carla da Silva, Coordenadora Técnica do CEDAC).

O término da reportagem com esses depoimentos reitera o propósito de tornar a vivência desse grupo um caso modelar. Assim, a reportagem extrapola os limites daquilo que é local para generalizar para outros biomas, outras regiões, atribuindo à comunidade Boa Esperança a responsabilidade pelo uso sustentado dos recursos da natureza, como forma inteligente de melhorar a renda econômica, sem devastar o bioma Cerrado.

A ênfase na responsabilidade que as populações locais, compostas de pequenos agricultores extrativistas, têm pelo aproveitamento econômico e pela conservação da natureza pode gerar o acobertamento e omissão, tanto dos grandes grupos empresariais como dos governos estaduais e federal, ou até mesmo o desrespeito à legislação relativa à preservação ambiental. Pinton e Aubertin (2000) elucidam que a valorização das atividades extrativistas que utilizam o manejo sustentável para a preservação da Floresta Amazônica tem delegado a responsabilidade pela proteção dos recursos naturais às populações tradicionais.

A discussão a respeito das populações tradicionais, vistas como incumbidas de conservar a natureza com suas atividades de manejo, está relacionada à idéia de desenvolvimento sustentável, sendo o conhecimento e as práticas dessas populações bons exemplos de desenvolvimento responsável; daí, a relação entre desenvolvimento 
sustentável e populações tradicionais ${ }^{12}$. A reportagem reforça esse aspecto quando situa a comunidade Boa Esperança, de Caldazinha/GO, na fronteira entre a devastação e a conservação.

A valorização do manejo sustentável ganhou força nas décadas de 60 e 70 do século passado, quando os antropólogos começaram a perceber em seus estudos etnográficos que os povos "selvagens" viviam bem, pois dispunham de técnicas adaptadas ao seu meio e às suas necessidades.

Muitos discursos ambientalistas atuais continuam valorizando a lição que os agrupamentos sociais mais simples, como os camponeses, podem dar ao mundo ocidental e preconizam a valorização dessas comunidades, chegando ao extremo de colocá-las como exemplo, como modelo, sem considerar as diferenças que existem não apenas entre os diversos segmentos sociais dessas comunidades, mas também na própria relação que elas estabelecem com o meio ambiente.

Em contrapartida, há também os pesquisadores que não acreditam nessa aplicação de modelos, ou seja, são contrários à transplantação de experiências, uma vez que cada região tem características físicas e geográficas próprias, assim como práticas culturais diferenciadas, o que ocasiona diferentes maneiras de lidar com o manejo. Torna-se difícil, então, pensar em projetos de manejo que sejam aplicáveis em outros biomas. Segundo Diegues (2000), muitos ambientalistas partem do princípio de que os problemas ambientais exigem soluções aplicáveis em todos os cantos do mundo:

Essas soluções mágicas para problemas como o desmatamento ou para a destruição de ricos ecossistemas costeiros são tidas como universais, pois parte-se do princípio que as relações entre as diversas sociedades e o mundo natural são as mesmas em todos os lugares, sobretudo na chamada era da globalização (DIEGUES, 2000, p. 2-3).

\footnotetext{
${ }^{12}$ Lembramos que anteriormente à idéia de desenvolvimento sustentável foi elaborado o conceito de ecodesenvolvimento, que estava mais direcionado aos países do Terceiro Mundo, para que o desenvolvimento procedesse em conformidade com um outro padrão, que não aquele implementado secularmente nos países do Primeiro Mundo. A esse respeito, ver discussão realizada por Leff (2001).
} 
Quando a fala da coordenadora técnica do CEDAC enfatiza que o projeto pode ser aplicado em qualquer outro bioma brasileiro, ela reitera a idéia de que o projeto é um exemplo, algo que já havia sido exposto na abertura da reportagem, na fala de Flávia Lippi: "Você vai conhecer o Projeto Baru, exemplo de desenvolvimento econômico aliado à preservação do Cerrado" (grifo nosso). Apresentar uma idéia como um modelo que pode ser replicável indistintamente é reducionista e configura-se como uma tendência do pensamento ambiental na valorização do manejo sustentável realizado pelas populações tradicionais para conservar os recursos naturais. $\mathrm{O}$ reducionismo consiste em querer fazer dos mais variados problemas ambientais situações que podem ser solucionadas com a aplicação de um determinado projeto que foi pensado em conformidade com uma realidade local.

Entretanto, a reportagem sobre o Projeto Baru não ressalta as contradições existentes entre as diferentes posições relativas à conservação dos recursos naturais, nem polemiza o desenvolvimento sustentável em face da atividade coletora. A análise detida da reportagem, graças à decupagem das imagens, evidencia esta falácia do trabalho jornalístico, que, no afã de espetacularizar o cotidiano na mídia, eleva uma experiência particular de manejo como modelo a ser seguido em qualquer contexto. $\mathrm{O}$ voluntarismo da reportagem prejudica a compreensão da diversidade de idéias, de temas para os quais podemos atentar numa observação mais geral do programa.

A idéia de manejo sustentável vai sendo construída desde o início da reportagem, especialmente pelos textos e falas autorizadas. Essa forma de organizar as imagens, arrolar os fatos e argumentos é uma maneira de convencer e apresentar as informações na direção de uma conclusão preestabelecida, o que reforça a idéia apresentada por Machado (2001, p. 104) de que uma notícia veiculada em um telejornal apresenta um processo significante que já vem determinado pela equipe de reportagem: "Sujeitos falantes diversos se sucedem, se revezam, se contrapõem uns aos outros, praticando atos de fala que se colocam nitidamente como o seu discurso com relação aos fatos relatados". 
Em outro trabalho no âmbito da análise de programas ecológicos exibidos na televisão brasileira, realizado por Andrade $(2003)^{13}$, verificamos que na análise do programa Globo Ecologia, edição exibida em março de 1994, que documentou a Estação Ecológica Mamirauá ${ }^{14}$, o referido autor também observa uma ausência de diálogos ao lado de depoimentos que se contrapõem, e, como conseqüência, questões polêmicas não são retratadas. Andrade (2003, p. 205) constata que esse é um problema característico dos programas televisivos, que são pouco afeitos à discussão e ao debate, pois são espaços destinados a mostrar a beleza, o espetacular. Nas suas palavras: "É como se as contraposições que provavelmente possam existir não se encaixassem nas normas do espetáculo televisivo, essencialmente visual e pouco afeito a polêmicas que descartem os efeitos estéticos e adentrem pelos exercícios de argumentação".

\section{Os significados das imagens e sons}

Todos os argumentos tecidos pelas falas, seja a dos moradores locais, seja a das locuções e da coordenadora técnica do CEDAC, juntamente com as imagens do local, das pessoas que vivem no campo, conduzem ao entendimento de que o manejo é sustentável e realizado por agricultores familiares, aproximando-os do conceito de populações tradicionais. Parece haver uma tentativa de convencimento de que o projeto surgiu dessa população, utilizando uma técnica tradicional, praticada espontaneamente por esse núcleo populacional desde sempre.

Cunha (1999) argumenta que a pertença à categoria "populações tradicionais" significa ter uma organização local e lideranças legítimas, associar-se às tradições de uso sustentável dos recursos naturais no

\footnotetext{
13 Texto originalmente apresentado como Tese (doutoramento) defendida no Instituto de Filosofia e Ciências Humanas da Universidade Estadual de Campinas, em 1998. A pesquisa se refere ao programa Amaral Neto, o Repórter, que esteve no ar entre os anos de 1969 e 1984, e ao programa Globo Ecologia, no ar desde 1990.

14 Andrade (2003) utiliza no texto a denominação Estação Ecológica por ser esta a empregada pelo programa na época das filmagens, mas esclarece que em 1996 a Estação Ecológica passou para outra categoria de conservação, a saber: Reserva de Desenvolvimento Sustentável.
} 
passado e aderir ao uso de técnicas de baixo impacto ambiental no futuro em um território delimitado.

A moradora Terezinha Rodrigues Campos é identificada como presidente da Associação Boa Esperança, mas, embora sua imagem e fala estejam presentes na reportagem, sua fala é curta e o tempo delegado ao seu depoimento é bem menor do que, por exemplo, ao concedido à coordenadora técnica do CEDAC, que está presente em várias inserções durante a reportagem. Percebemos, então, que algumas pessoas estão autorizadas pelo programa para falar sobre o projeto, pois há tratamento diferenciado quanto ao tempo de cada fala e ao número de inserções, o que define muito bem o papel de cada entrevistado, reforçando a dicotomia entre a prática cotidiana das populações tradicionais e a introdução de novos hábitos com as atividades extensionistas planejadas por técnicos extensionistas ${ }^{15}$.

Provavelmente, as pessoas da comunidade aparecem para dar sentido à narrativa que o programa escolheu para apresentar o manejo sustentável do baru: o resgate e a valorização dos conhecimentos tradicionais (socialmente justo); o aumento da renda familiar das pessoas que vivem no campo (economicamente viável); a garantia de não comprometer o ambiente (ambientalmente correto). Nesse sentido, a reportagem valoriza a comercialização dos produtos naturais, priorizando a viabilidade comercial do desenvolvimento sustentável.

A reportagem, no entanto, não fez menção às dificuldades enfrentadas pela comunidade na incorporação das novas atividades relacionadas à coleta do baru e sua comercialização, ou à forma como se deu essa mudança na maneira de sobreviver utilizando os recursos da terra. Tais questões são apagadas para mostrar os aspectos do desenvolvimento sustentável, considerando os valores sociais, econômicos e ambientais dos produtos obtidos a partir do manejo sustentável.

Embora este estudo não tenha a intenção de generalizar a abordagem sobre desenvolvimento sustentável apresentada pelo

\footnotetext{
15 Mais uma vez, nos referimos ao trabalho de Andrade (2003), na análise mais detida que realizou sobre o programa Globo Ecologia, reportagem sobre Mamirauá, mostrando que também o tempo maior é concedido aos pesquisadores que vivem na reserva, fato que os autoriza a falar.
} 
Repórter Eco, na reportagem sobre o Projeto Baru percebemos a contribuição da televisão para a discussão sobre um tema tão polêmico como o Desenvolvimento Sustentáve ${ }^{16}$. Ao se estudar a mídia por meio de uma análise detalhada de um programa de televisão, como o Repórter Eco, é possível perceber, não só pelo que foi escolhido para ser exibido, como também pelo que não aparece na reportagem, as polêmicas em torno do conceito de desenvolvimento sustentável, o que torna viável uma reflexão crítica sobre temas que permeiam a educação ambiental.

16 A UNESCO tem orientado a mudança da denominação Educação Ambiental para Educação para o Desenvolvimento Sustentável (em 2005, foi instituída a década da Educação para o Desenvolvimento Sustentável). Essa tentativa de mudança tem causado certa polêmica entre os educadores ambientais da América Latina e do Caribe e algumas críticas têm sido colocadas. Com base em González Gaudiano (2007), destacamos algumas: a situação dos países da América Latina e do Caribe é bem diferente da dos países desenvolvidos que aceitam a atual denominação; a dificuldade em relação à carga semântica que a palavra desenvolvimento carrega; a passagem de educação ambiental para educação para o desenvolvimento sustentável não garante a mudança do enfoque conservacionista/naturalista para um enfoque mais sistêmico, como tem sido alegado pela UNESCO. 


\section{Referências bibliográficas}

ALMEIDA, M. J. de. Imagens e sons: a nova cultura oral. São Paulo: Cortez Editora, 1994.

ANDRADE, T. de. Ecológicas manhãs de sábado: o espetáculo da natureza na televisão brasileira. São Paulo: Annablume: Fapesp, 2003.

BORTOLOZZI, A. Educação Ambiental e o ensino de geografia: Bacias dos rios Piracicaba, Capivari e Jundiaí. 268 p. 1997. Tese (Doutorado em Educação) - Faculdade de Educação, Universidade Estadual de Campinas, Campinas, 1997.

BOURDIEU, P. Sobre a televisão. $6^{\mathrm{a}}$ ed. Tradução de Maria Lúcia Machado. Rio de Janeiro: Jorge Zahar Editor, 1997.

CARVALHO, L. M. A temática ambiental e a escola de 1². Grau. 1989. Tese (Doutorado em Educação) - Faculdade de Educação, Universidade de São Paulo, São Paulo, 1989.

CUNHA, M. C. da. Populações Tradicionais e a Convenção da Diversidade Biológica. Estudos Avançados. V. 36; n.13, p.147-163, 1999.

DIEGUES, A. C. Etnoconservação da natureza: enfoques alternativos. In:

Etnoconservação. Novos rumos para a proteção da natureza nos trópicos. São Paulo: Hucitec, 2000. p.01-46.

DIEGUES, A. C.; ARRUDA, R. Saberes Tradicionais e Biodiversidade no Brasil. Brasília: Ministério do Meio Ambiente; São Paulo: USP, 2001.

GONZÁLEZ GAUDIANO, E. Educación ambiental: trayectorias, rasgos y escenarios. México: Plaza y Valdés, S.A. de C. V., 2007.

GUIDO, L. de F. E. Os meios de comunicação social e sua influência na representação de ambiente em alunos do ensino fundamental In: REUNIÃO 
ANUAL DA ANPED, 23, 2000, Caxambu. Anais... Caxambu: Anped, set.2000, 1 CD ROM.

LEFF, Enrique. Saber ambiental. Sustentabilidade, racionalidade, complexidade, poder. Petrópolis: Vozes, 2001.

MACHADO, A. A Televisão levada a sério. 2a ed. São Paulo: Editora Senac, 2001.

MÁXIMO-ESTEVES, L. Da teoria à Prática: Educação Ambiental com a crianças pequenas ou O Fio da História. Porto: Porto Editora, 1998.

OSTMAN, R.; PARKER, J. L. A Public's Environmental Information Sources and Evaluations of Mass Media. Journal of Environmental Education, v. 18, n. 2, p. 9-17, 1986.

PINTON, F.; AUBERTIN, C. Extrativismo e desenvolvimento regional. In: A floresta em jogo. O extrativismo na Amazônia central. Editora científica Laure Emperaire; São Paulo: Editora da Unesp: imprensa oficial do Estado, 2000. p. 151-159. 